\title{
Evidence for a Glycosidic Linkage between Chitin and Glucan in the Cell Wall of Candida albicans
}

\author{
By RUDEE SURARIT, PRAMOD K. GOPAL AND \\ MAXWELL G. SHEPHERD* \\ Experimental Oral Biology Unit, Faculty of Dentistry, University of Otago, PO Box 647, \\ Dunedin, New Zealand
}

(Received 2 December 1987)

\begin{abstract}
The alkali-insoluble glucan was isolated from regenerating spheroplasts and intact cells of Candida albicans. Sequential enzymic hydrolysis of this fraction by Zymolyase 100T and purified chitinase and subsequent gel filtration produced a fraction which was enriched in glycosaminoglycans. This fraction was analysed by partial acid hydrolysis, TLC and GLC-MS. The GLC-MS peaks identified included 2,3,4,6-tetra- $O$-methylglucitol acetate and 2,3,4-tri- $O$ methylglucitol acetate of $\beta$-1,6-glucan and the 3,6-di- $O$-methyl-2- $N$-methylglucosaminitol acetate of chitin. In addition, 3-O-methyl-2- $N$-methylglucosaminitol acetate was identified, which indicated a branch point in chitin. These data provide evidence for a covalent linkage between chitin and $\beta$ - $(1,6)$-glucan through a glycosidic linkage at position 6 of $\mathrm{N}$ acetylglucosamine and position 1 of the glucose in the glucan.
\end{abstract}

\section{INTRODUCTION}

The composition and structure of the Candida albicans cell wall has recently been reviewed by Shepherd (1987). The major components of the wall are mannan, $\beta-(1,3)$ - and $\beta-(1,6)$-glucan and a small quantity of chitin (Sullivan et al., 1983). Although there have been reports on the structural analysis of cell wall glucans in C. albicans (Bishop et al., 1960; Yu et al., 1967; Gopal et $a l ., 1984 b$ ), the arrangement of the glucan matrix throughout the wall is not clearly understood. Gopal et al. (1984c) suggested that there are three types of structural glucan in the $C$. albicans cell wall : a $\beta-(1,3)-/ \beta-(1,6)$-glucan complexed with chitin adjacent to the plasma membrane and two highly branched glucans with $\beta-(1,3)$ and $\beta-(1,6)$ linkages, respectively. However, there are no reports on the nature of the linkages between glucan, mannan and chitin in the $C$. albicans cell wall.

Molano et al. (1980) have shown that in Saccharomyces cerevisiae more than $90 \%$ of the total chitin is located in the septa with a smaller amount evenly distributed in the lateral walls. In $C$. albicans the majority of the chitin is located in the bud scars but there is a layer of chitin close to the membrane and small portions distributed throughout the wall (Tronchin et al., 1981). The alkali-insoluble glucan is composed predominantly of $\beta-(1,3)$ - and $\beta-(1,6)$-linked glucans (Gopal et al., 1984c). These glucans are highly branched and it is not at all clear why they are insoluble in alkali. The observation that glucans can be solubilized after treatment of the alkali-insoluble fraction with chitinase provides indirect evidence for a linkage between chitin and glucans. Sietsma \& Wessels (1979) produced some evidence that amino acids, particularly lysine, may be involved in linking the chitin and glucan polymers in Schizophyllum commune. In a recent study, Mol \& Wessels (1987) have reported the presence of glucosaminoglycans and their linkage to glucans in Saccharomyces cerevisiae after nitrous acid treatment of the alkali-insoluble fraction. In this paper we provide evidence for a covalent linkage between chitin and $\beta-(1,6)$-glucan in $C$. albicans. 


\section{METHODS}

Organism and culture conditions. Candida albicans (ATCC 10261) was the strain used throughout this work. The organism was maintained on malt extract agar slopes. Yeast cells were prepared in shake flask cultures containing glucose/salts/biotin medium (Shepherd \& Sullivan, 1976). Mid-exponential-phase cells (16-18 h), harvested and washed by centrifugation, were used throughout the study and are referred to as intact yeast cells.

Enzymes. The hydrolytic enzymes used in this study were Zymolyase 100T (Seikagaku Kogyo Co.), purified $\beta$ (1,6)-glucanase from Penicillium brefeldianum (Schep et al., 1984), $\alpha$-amylase from porcine pancreas (Boehringer Mannheim) and chitinase purified according to the procedure of Molano et al. (1977).

Preparation of spheroplasts. Spheroplasts from yeast cells were prepared essentially as described by Hubbard $e t$ al. (1986). Cell suspensions were washed twice with distilled water by centrifuging at $6000 \mathrm{~g}$ for $10 \mathrm{~min}$ and resuspended to $1.0 \times 10^{8}$ cells ml ${ }^{-1}$ in spheroplasting buffer $\left(0 \cdot 1 \mathrm{M}-\mathrm{Tris} / \mathrm{HCl}, \mathrm{pH} 7.2\right.$, containing $\left.0.5 \mathrm{M}-\mathrm{MgSO}_{4}\right)$ and $20 \mathrm{~mm}$-2-mercaptoethanol. After preincubation of the cell suspension for $30 \mathrm{~min}$ at $35^{\circ} \mathrm{C}$ in a gyratory shaker

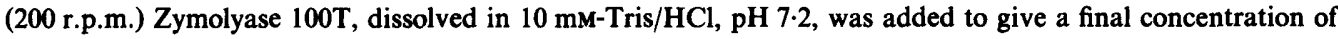
1 unit $\mathrm{ml}^{-1}$. The flask was sealed with Parafilm and incubated with shaking at a rate just sufficient to maintain the cells in suspension (approx 100 r.p.m.) at $35^{\circ} \mathrm{C}$ for $60-90 \mathrm{~min}$. Spheroplast formation was monitored by phase contrast microscopy and the presence of spheroplasts confirmed by subjecting the cells to osmotic lysis. Spheroplasts were harvested by gentle centrifugation $(150 \mathrm{~g}$ for $5 \mathrm{~min}$ ) and washed three times with spheroplasting buffer.

Regeneration of spheroplasts. This was done in $0 \cdot 1 \mathrm{M}-\mathrm{Tris} / \mathrm{HCl}, \mathrm{pH} 7 \cdot 2$, containing $0.5 \mathrm{M}-\mathrm{MgSO}_{4}$ and $5.0 \mathrm{mM}$ glucose (regeneration medium) at $30^{\circ} \mathrm{C}$, essentially as described by Gopal et al. (1984 a). The criteria used for regeneration were: (i) incorporation of $\left[{ }^{14} \mathrm{C}\right]$ glucose into cells, (ii) restoration of osmotic stability, (iii) appearance of a phase-bright cell wall under the phase contrast microscope.

Enzymic hydrolysis of $\beta-(1,3)$ - and $\beta-(1,6)$-glucans in regenerated spheroplasts. At 30 min intervals, four samples $(2.0 \mathrm{ml}$ each) were removed from the regenerating spheroplast mixture. Total incorporation of $[\mathrm{U}-14 \mathrm{C}] \mathrm{glucose}$ was measured in one $2.0 \mathrm{ml}$ sample on a GF/C filter as described by Gopal et al. (1984a). The other three samples were filtered through GF/C filters and the filters washed with 3 vols of spheroplasting buffer. The filters were then placed in $1.0 \mathrm{ml} 0.1 \mathrm{M}$-sodium phosphate buffer, $\mathrm{pH} 7.0$, containing $0.02 \%$ sodium azide and $50 \mu \mathrm{g}$ chloramphenicol ml-1. After incubation at $37^{\circ} \mathrm{C}$ for $18 \mathrm{~h}, 2.0 \mathrm{ml} 95 \%(\mathrm{v} / \mathrm{v})$ ethanol was added. The insoluble residues were recovered by centrifugation and the radioactivity in the supernatants counted in Triton X-100/ toluene/ethanol scintillant. This procedure was repeated with the residue from one sample using the following enzymes: $\alpha$-amylase ( $1 \mathrm{mg} \mathrm{ml}^{-1}$ in 50 mM-sodium phosphate buffer, pH 6.9) followed by $\beta$-(1,6)-glucanase $\left(0.2\right.$ units $\mathrm{ml}^{-1}$ in $0.2 \mathrm{M}$-sodium acetate buffer, $\mathrm{pH} \mathrm{4.2)}$ and finally Zymolyase $100 \mathrm{~T}\left(1 \mathrm{mg} \mathrm{ml}^{-1}\right.$ in $0.1 \mathrm{M}$-sodium acetate buffer, $\mathrm{pH}$ 5.4). Although pH 7.2 was the optimum for the use of Zymolyase 100T in the preparation of spheroplasts, pH 5.4 was chosen for glucan analysis experiments as it was the optimum pH for $\beta$-(1,3)-glucanase activity. The other two samples were hydrolysed in the same manner but different sequences of enzymes were used. In some experiments an additional incubation with crude chitinase (Sigma; $1 \mathrm{mg} \mathrm{m}^{-1}$ ) was done in $0 \cdot 1 \mathrm{M-}$ sodium phosphate buffer, pH 6.3. All buffers contained $50 \mu \mathrm{g}$ chloramphenicol ml-1.

Enzymic hydrolysis of the glucan-chitin complex. Wall glucan was obtained from either mid-exponential-phase yeast cells or regenerated spheroplasts $\left(200 \mathrm{ml}, 2 \times 10^{10}\right.$ cells) by adding 2 vols of cold $\left(-20^{\circ} \mathrm{C}\right)$ methanol and leaving overnight at $4{ }^{\circ} \mathrm{C}$. The precipitate was collected by centrifugation at $6000 \mathrm{~g}$ for 20 min and washed twice with $66 \%(\mathrm{v} / \mathrm{v})$ ethanol $(10000 \mathrm{~g}, 20 \mathrm{~min})$. The cytoplasmic component was then removed by extraction with $1 \mathrm{M}$ $\mathrm{KOH} /$ ethanol $(1: 2, \mathrm{v} / \mathrm{v})$ at $60^{\circ} \mathrm{C}$ for $20 \mathrm{~min}$ and the residue washed until neutral with $66 \%(\mathrm{v} / \mathrm{v})$ ethanol $(10000 \mathrm{~g}$, $20 \mathrm{~min}$ ). The cell wall pellet was incubated sequentially with buffer to check for autolysis, and then with specific enzymes as described below. The pellet was resuspended in $2 \mathrm{ml} 0.1 \mathrm{M}$-sodium phosphate buffer, pH 7.0, containing $0.02 \%$ sodium azide and $50 \mu \mathrm{g}$ chloramphenicol ml-1 and incubated at $37^{\circ} \mathrm{C}$ with shaking for $18 \mathrm{~h}$. The supernatant was retained after centrifugation at $10000 \mathrm{~g}$ for $20 \mathrm{~min}$. The pellet was resuspended in $2 \mathrm{ml}$ of the same buffer and incubated with $\alpha$-amylase ( 20 units) for another $18 \mathrm{~h}$ under the same conditions. The enzyme reaction was terminated by heating at $100{ }^{\circ} \mathrm{C}$ for $5 \mathrm{~min}$, and the supernatant and pellet separated by centrifugation at $10000 \mathrm{~g}$ for $20 \mathrm{~min}$. The pellet was washed once with the same buffer $(2.0 \mathrm{ml})$, resuspended in $0 \cdot 1 \mathrm{M}$-sodium acetate buffer, pH 5.4, and incubated with 5 units of Zymolyase 100T for another $18 \mathrm{~h}$ under the same conditions. Inactivation of the enzyme and centrifugation were done as described above. The pellet was washed with $0 \cdot 1 \mathrm{M}-$ sodium acetate buffer, $\mathrm{pH} \mathrm{5.4}$, resuspended in $2 \mathrm{ml} 0.1 \mathrm{M}$-sodium phosphate buffer, $\mathrm{pH} \mathrm{6.3}$, containing $0.02 \%$ sodium azide and $50 \mu \mathrm{g}$ chloramphenicol $\mathrm{ml}^{-1}$, and incubated with purified chitinase $(2 \mathrm{units} ; 0.2 \mathrm{ml})$ at $37^{\circ} \mathrm{C}$ for $18 \mathrm{~h}$. The suspension was then heated at $100^{\circ} \mathrm{C}$ for $5 \mathrm{~min}$ and centrifuged as described above.

The supernatant from each enzyme incubation was concentrated by lyophilization and applied to a Bio-Gel P-30 column $(1.0 \times 15 \mathrm{~cm})$ which had been equilibrated with $0.1 \mathrm{M}$-acetic acid at room temperature. Fractions $(2 \mathrm{ml})$ were collected at a flow rate of $2 \mathrm{ml} \mathrm{h}^{-1}$ and assayed for total carbohydrate using the phenol/sulphuric acid assay (Dubois et al., 1956). The fractions that were excluded from the gel were pooled and rechropatographed on a Sephacryl S-300 column $(0.5 \times 40 \mathrm{~cm})$ in $0.1 \mathrm{M}$-acetic acid, at a flow rate of $2.5 \mathrm{ml} \mathrm{h}^{-1}$. Fractions $(0.5 \mathrm{ml})$ were 
collected and assayed for carbohydrate content. Fractions containing carbohydrate were pooled and lyophilized. The freeze-dried samples were resuspended in the appropriate buffer and incubated with either $\beta$ - $(1,6)$-glucanase, Zymolyase $100 \mathrm{~T}$ or chitinase. The supernatant from each enzyme incubation was rechromatographed on the same Sephacryl S-300 column under the same conditions. The experiment with spheroplasts which had regenerated in the presence of $\left[\mathrm{U}-{ }^{14} \mathrm{C}\right] \mathrm{glucose}$ was done in the same way.

Chemical analysis of regenerated cell wall : monosaccharide analysis. Polysaccharide and oligosaccharide fractions $(50 \mathrm{mg})$ were hydrolysed by refluxing the residue with $2.5 \mathrm{M}-\mathrm{H}_{2} \mathrm{SO}_{4}(5 \mathrm{ml})$ at $100{ }^{\circ} \mathrm{C}$ for $4 \mathrm{~h}$. After hydrolysis, solid barium carbonate was added to the solution, under nitrogen. The barium salt was removed by filtration and excess barium ions removed with Dowex $50 \mathrm{H}^{+}$. Each hydrolysate was concentrated to $2 \mathrm{ml}$ under reduced pressure. Monosaccharides were separated by paper chromatography, by TLC or by GLC of their alditol peracetate derivatives (Borchardt \& Piper, 1970).

Partial acid hydrolysis. Partial acid hydrolysates of cell wall polysaccharides, starch, laminarin and pustulan were prepared by hydrolysis with $1.0 \mathrm{M}-\mathrm{H}_{2} \mathrm{SO}_{4}$ under vacuum in a sealed tube for $30 \mathrm{~min}$ at $110^{\circ} \mathrm{C}$. The hydrolysates were then neutralized with solid barium carbonate and deionized with Dowex $50 \mathrm{~W}-\mathrm{X} 8\left(\mathrm{H}^{+}\right)$. The partial acid hydrolysate of chitin was prepared in the same way using $3 \mathrm{M}-\mathrm{HCl}$. The oligomers from each polysaccharide hydrolysis were identified by paper chromatography and TLC.

Paper chromatography. Descending paper chromatography was done using Whatman no. 1 paper. Solvent systems used were propan-1-ol/ethyl acetate/water $(7: 1: 2$, by vol.) and ethyl acetate/pyridine/water $(10: 4: 3$, by vol.). Sugar spots were detected using the alkaline silver staining method of Trevelyan et al. (1950).

$T L C$. This was done on silica gel pre-coated aluminium sheets $(0.2 \mathrm{~mm}$ thickness, $12 \times 20 \mathrm{~cm})$. Plates were activated by pre-heating at $100^{\circ} \mathrm{C}$ for $1 \mathrm{~h}$. A mixture of oligosaccharides was applied as $1-2 \mu l$ spots on cooled plates which were then chromatographed in propan-1-ol/acetone/1 M-lactic acid, $(7: 1: 1$, by vol.). Sugar spots were detected by spraying the developed chromatogram with aniline/diphenylamine/acetone $/ 80 \%(w / v)$ phosphoric acid $(4 \mathrm{ml}: 4 \mathrm{~g}: 200 \mathrm{ml}: 30 \mathrm{ml})$ and heating at $100{ }^{\circ} \mathrm{C}$ for $15 \mathrm{~min}$. Sugars appeared as coloured spots on a white background.

Methylation analysis. The methylation process was done by the modified method of Hakomori (1964), which has been described in detail by Gopal et al. $(1984 \mathrm{~b})$. The alditol peracetates prepared from neutralized hydrolysates of methylated polysaccharides (Borchardt \& Piper, 1970) were analysed with a Varian model 3700 capillary GLC equipped with a flame ionization detector. Peak areas were determined using a Varian 4270 integrator and the column was an Altech RSL-150 no. 13640 (30 $\mathrm{m} \times 0.32 \mathrm{~mm}$ i.d.).

$G L C-M S$. The permethylated alditol derivatives of pustulan, laminarin and the $\mathrm{CI}$ fraction were analysed by GLC-MS using a Hewlett Packard (model HP5985B) GC-MS. This work was done at the Forest Research Institute, Rotorua, New Zealand.

\section{RESULTS}

\section{Regeneration of spheroplasts}

The incorporation of $\left[{ }^{14} \mathrm{C}\right]$ glucose into regenerating $C$. albicans spheroplasts is shown in Table 1. The alkali-insoluble fraction was further analysed by specific enzymic hydrolysis and gel permeation chromatography. The results showed that $5.4 \%$ of the counts were released by $\alpha$ amylase, $12 \%$ by Zymolyase $100 \mathrm{~T}$ and $47 \%$ by purified chitinase. The soluble products from Zymolyase and chitinase degradation were fractionated by gel chromatography on a Bio-Gel P-30 column (Fig. 1). One fraction from each enzyme incubation (designated ZI and CI) was excluded from the gel and appeared in the void volume. These fractions contained $35 \%$ and $86 \%$ of the soluble radioactivity released by Zymolyase $100 \mathrm{~T}$ and purified chitinase, respectively. The included fractions (designated ZII and CII) were lower- $M_{\mathrm{r}}$ products which contained $65 \%$ and $14 \%$ of the radioactivity released by Zymolyase $100 \mathrm{~T}$ and purified chitinase, respectively. These hydrolytic products were analysed by descending paper chromatography. Fraction ZII chromatographed as glucose, laminaribiose and oligosaccharides of the laminarin series. Fraction CII chromatographed as $\mathrm{N}$-acetylglucosamine, glucose, chitobiose and oligosaccharides. The fractions excluded from the Bio-Gel column (CI and ZI) both remained at the origin.

\section{Characterization of $Z I$ and $Z I I$}

The monosaccharide compositions of ZI and ZII were determined from GLC of alditol acetate derivatives prepared from total acid hydrolysates of these fractions. The relative amount of each sugar was determined from the area under the peak; ZI contained $100 \%$ glucose, 


\section{Table 1. $D-\left[U-{ }^{14} C\right]$ Glucose incorporation into regenerating spheroplasts}

Spheroplasts were suspended in $100 \mathrm{ml}$ regeneration medium containing $\mathrm{D}-\left[\mathrm{U}-{ }^{14} \mathrm{C}\right] \mathrm{glucose}$ $\left(1.0 \times 10^{6}\right.$ c.p.m. $\mathrm{ml}^{-1}$; specific activity, $\left.7.4 \mathrm{GBq} \mathrm{ml}^{-1}\right)$ at a density of $1.0 \times 10^{8}$ cells ml $^{-1}$. After $6 \mathrm{~h}$ incubation at $37^{\circ} \mathrm{C}$, the regenerating spheroplasts were harvested and fractionated as described in Methods. The alkali-insoluble glucan was degraded by enzymic hydrolysis with $\alpha$-amylase, Zymolyase 100T and purified chitinase.

\section{Fraction}

Total radioactivity incorporated Methanol-precipitated pellet

Alkali-insoluble fraction

Counts released by $\alpha$-amylase

Counts released by Zymolyase

Counts released by chitinase

Radioactivity
(c.p.m.)
1852900
1087600
589250
31819
71800
279174

Percentage radioactivity

100

$5 \cdot 4$

12

47

whereas ZII contained $92 \%$ glucose and $8 \%$ mannose. No other sugars were detected. The ZI fraction was resistant to further digestion by either Zymolyase $100 \mathrm{~T}$ or purified chitinase, but low- $M_{\mathrm{r}}$ oligosaccharides of the $\beta-(1,6)$-glucan series were released when this fraction was incubated with purified $\beta$-(1,6)-glucanase.

\section{Characterization of $C I$}

Total acid hydrolysis of CI gave the monosaccharides glucose and glucosamine. The CI fraction was resistant to further digestion by either chitinase or Zymolyase 100T but was partially degraded by purified $\beta-(1,6)$-glucanase. The oligosaccharides released by the $\beta-(1,6)-$ glucanase did not run on TLC as a $\beta$ - $(1,6)$-glucan series. TLC of the partial acid hydrolysates of the CI fraction gave oligosaccharides which did not correspond to either the $\beta-(1,3)$-glucan or the $\beta$ - $(1,6)$-glucan series. The material released by the $\beta$-(1,6)-glucanase was a polyglucan since total acid hydrolysis gave glucose only.

The CI fraction, laminarin and pustulan were methylated and, following hydrolysis, alditol acetate derivatives of these permethylated substances were prepared. The $O$-methylated alditol acetates produced after hydrolysis of each glucan were separated by GLC and the peaks identified by GLC-MS. The MS species were identified from the $m / e$ tables provided by Bjorndal et al. (1967) for glucose derivatives, and by Wong et al. (1980) for amino sugar derivatives. Pustulan yielded one major peak, identified as 2,3,4-tri-O-methylglucitol $(87 \%)$, and minor peaks of 2,3,4,6-tetra-O-methylglucitol $(16 \%)$ and 2,4 -di-O-methylglucitol $(5 \%)$. With laminarin the major peak was 2,4,6-tri-O-methylglucitol $(74 \%)$. The minor peaks were $2,3,4,6-$ tetra-O-methylglucitol $(8 \%)$ and 2,4 -di-O-methylglucitol $(7 \%)$ derivatives.

GLC of the derivatized CI fraction yielded one major and three minor peaks. Some of the peaks were identified from retention times and also by spiking the samples with $O$-methylated alditol acetates of laminarin and pustulan. Fig. 2 shows that the major peak of $\mathrm{CI}$ (peak 3) did not correspond to either the 2,3,4-tri- $O$-methyglucitol (peak 2) or 2,4,6-tri- $O$-methylglucitol (peak 5) derivatives characteristic of pustulan and laminarin, respectively. The CI derivatives were further analysed by GLC-MS. The molecular and fragmentation ions of the derivatized sugars are summarized in Table 2 . In the recorded spectra the base peak was $m / e 43\left(\mathrm{CH}_{3} \mathrm{CO}^{+}\right)$. Only peaks having an intensity of more than $10 \%$ of the base peak are included. The major peak of the CI fraction (Fig. $2 a$, peak 3) was identified as 3,6-di-O-methyl-2- $N$-methylglucosaminitol acetate. Other peaks identified included 2,3,4,6-tetra- $O$-methyl (peak 1) and 2,3,4-tri- $O$-methyl (peak 2) derivatives of glucose. Of most significance was the identification of the 3-O-methyl derivative of $\mathrm{N}$-acetylglucosamine (peak 4) (Fig. 2) as this defines the linkage between the $\mathrm{N}$ acetylglucosamine of chitin and glucose of $\beta$-(1,6)-glucans. The types of linkages and composition of each peak are summarized in Table 3. 

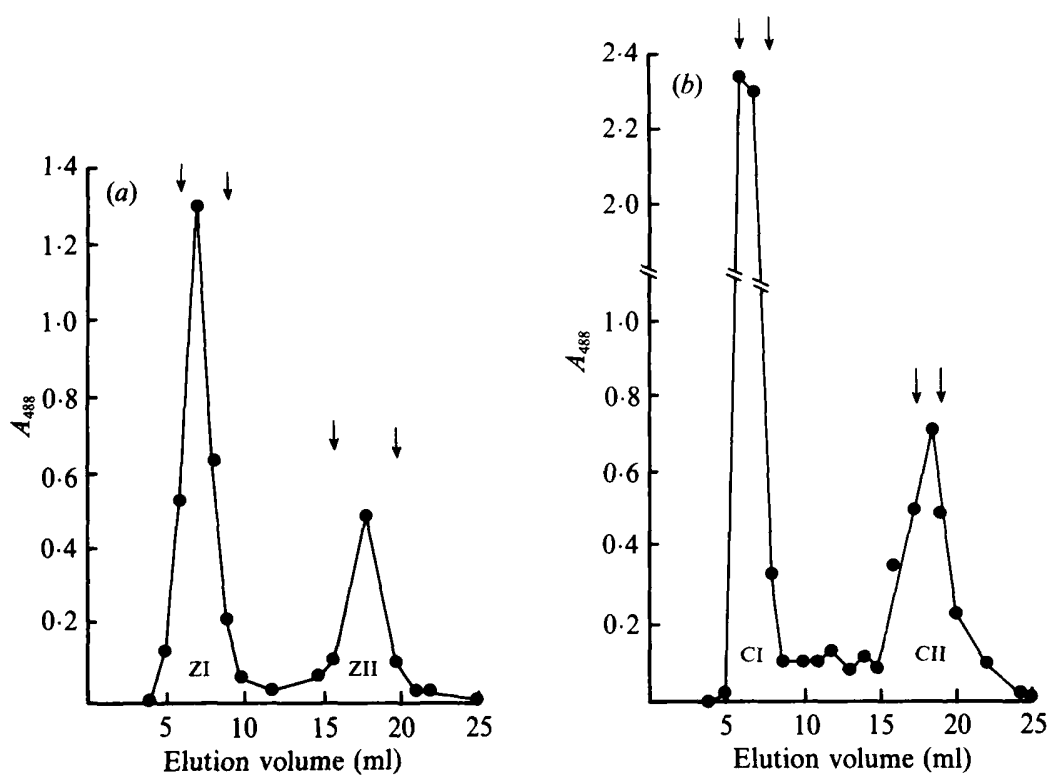

Fig. 1. Bio-Gel P-30 column chromatography of degradation products from alkali-insoluble glucan. The alkali-insoluble glucan from regenerated spheroplasts was hydrolysed sequentially with Zymolyase $(a)$ and purified chitinase $(b)$. The soluble products were fractionated on Bio-Gel P-30. The column $(1.0 \times 15 \mathrm{~cm})$ was equilibrated and eluted with $0.1 \mathrm{M}$-acetic acid at a flow rate of $2 \mathrm{ml} \mathrm{h}^{-1}$. Fractions of $0.75 \mathrm{ml}$ were collected and the carbohydrate content of each fraction was determined by the phenol/sulphuric acid method. The fractions, ZI, ZII and CI, CII, were pooled as indicated. The void volume of this column, determined with blue dextran, was $6 \mathrm{ml}$.

Analysis of the alkali-insoluble glucan in the yeast cell wall by sequential enzyme hydrolysis

Although evidence had been obtained for a glycosidic linkage between glucan and chitin in the regenerated spheroplast cell wall it was of interest to determine whether a similar linkage was present in growing yeast cells of $C$. albicans. For these experiments the growth of $C$. albicans in liquid medium was stopped after $16 \mathrm{~h}$ by the addition of 2 vols methanol; the precipitate was collected by centrifugation, washed with $66 \%(\mathrm{v} / \mathrm{v})$ ethanol and then treated with $1 \mathrm{M}$ $\mathrm{KOH} /$ ethanol $(1: 2, \mathrm{v} / \mathrm{v})$. Enzymic hydrolysis and gel chromatography of the alkali-insoluble material on Bio-Gel P-30 showed a similar pattern to that obtained from regenerating spheroplasts (data not shown). Analysis of the products after total acid hydrolysis confirmed that ZI was a polyglucan, whereas CI consisted of a mixture of glucosamine and glucose.

\section{DISCUSSION}

It is generally accepted that the microfibrillar glucan and chitin polymers endow rigidity on the cell wall of most fungi and that these polymers form the scaffolding to which mannoproteins are bound (for a review, see Shepherd, 1987). The strongest evidence for this contention in $C$. albicans is the restoration of osmotic stability in regenerating spheroplasts when glucan and chitin is formed on the cells; mannoproteins are not attached (Gopal et al., 1984a). An important feature in providing rigidity to the fungal wall is the cross-linking of polymers, particularly chitin and glucan. On fractionation this material is isolated as an alkali-insoluble fraction. In this study, Zymolyase $100 \mathrm{~T}$ released $12 \%$ of the total radioactivity from the alkaliinsoluble fraction of $C$. albicans. Zymolyase $100 \mathrm{~T}$ is a highly purified preparation of exo- and endo- $\beta-(1,3)$-glucanases which is known to be free from $\alpha-(1,4)-, \beta-(1,4)-\beta-(1,2)$ - and $\beta-(1,6)-$ glucanases (Kitamura \& Yamamoto, 1972), therefore indicating the presence of $\beta$-(1,3)-glucan chains in this fraction. Analysis of the material released by Zymolyase 100T on a Bio-Gel P-30 


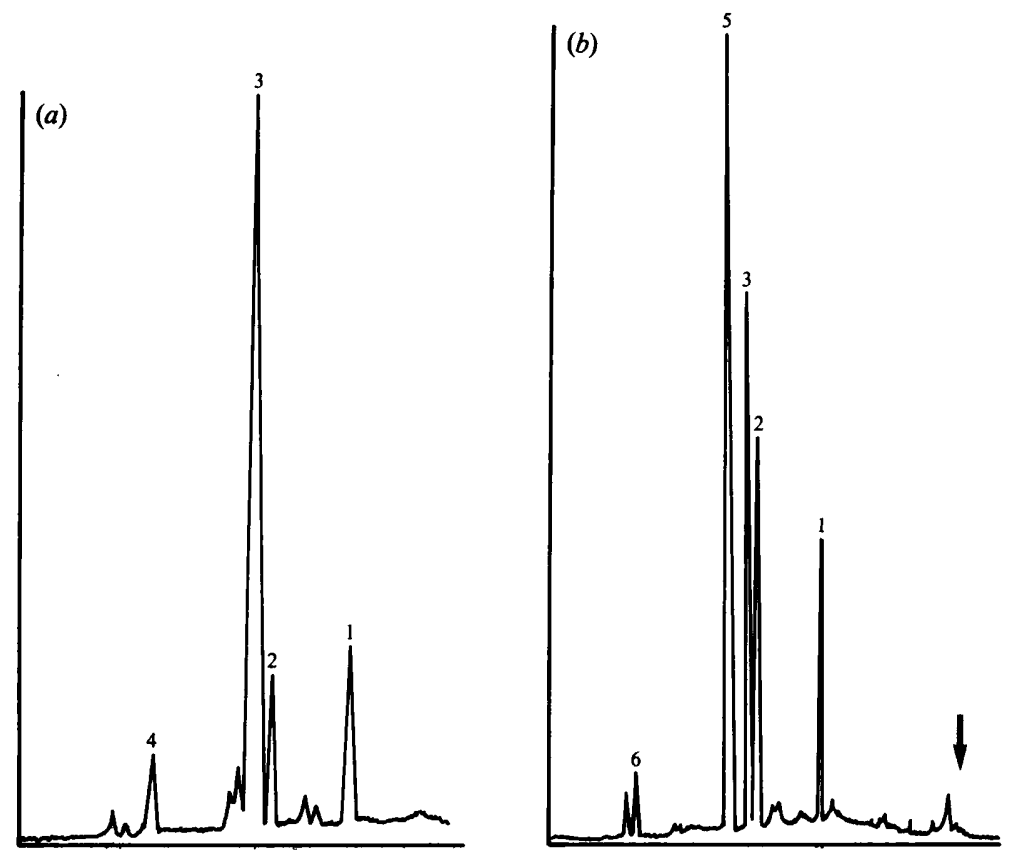

Fig. 2. GLC alditol acetate derivatives of the methylated and hydrolysed CI fraction: Alditol acetate derivatives of the methylated CI fraction were separated on an AITech RSL-150 \#13640 column (a). The peaks were identified either by mass spectroscopy of the fragmentation pattern of the separated derivatives (see Table 2) or by spiking the samples with alditol acetates of methylated standard glucans, e.g. laminaran and pustulan $(b)$. The identification of the peaks are as follows: 2,3,4,6-tetra- $O$ methylglucitol (1); 2,3,4-tri- $\mathrm{O}$-methylglucitol (2); 3,6-di-O-methyl-2- $\mathrm{N}$-methylglucosaminitol (3); 3-Omethyl- $N$-methylglucosaminitol (4); 2,4,6-tri- $O$-methylglucitol (5); 2,4-di- $O$-mẹthylglucitol (6).

Table 2. Major fragment ions $(\mathrm{m} / \mathrm{e})$ in the mass spectra of permethylated alditol acetates from the CI fraction

\begin{tabular}{ccc} 
Peak no.* & $\begin{array}{c}\text { Position of } \\
\text { O-methyl groups }\end{array}$ & \multicolumn{1}{c}{$\begin{array}{c}\text { Characteristic spectral ion } \\
(\mathrm{m} / \mathrm{e})\end{array}$} \\
1 & $2,3,4,6$ & $43,45,71,87,101,117,129,143,161,205$ \\
2 & $2,3,4$ & $43,45,87,99,101,117,233$ \\
3 & 3,6 & $43,45,74,87,116,124,142,158,170,202,233$ \\
4 & 3 & $43,45,74,87,116,124,142,158,202,261$ \\
& &
\end{tabular}

column revealed two fractions. Paper chromatography and TLC of the included fraction (ZII) showed that it consisted of oligosaccharides of the $\beta$ - $(1,3)$-glucan series. The excluded fraction (ZI) was a glucan which could be partially degraded by $\beta$-(1,6)-glucanase. We conclude that $\mathrm{ZI}$ is a mixed $\beta-(1,3)-/ \beta-(1,6)$-glucan which may have a highly branched structure since neither $\beta$ $(1,3)$ - nor $\beta-(1,6)$-glucanases could digest all of the linkages in the polymer.

Total acid hydrolysis of the Zymolyase-resistant residues showed that both glucan and chitin were present since glucose and glucosamine were the monosaccharides detected. Further incubation of the Zymolyase-resistant material with purified chitinase resulted in the release of about $47 \%$ of the radioactivity. This material was separated into two fractions (CI and CII) on the Bio-Gel P-30 column. Analysis of the included CII fraction by paper chromatography and TLC showed that it contained $\mathrm{N}$-acetylglucosamine, glucose, chitobiose and a trace of mannose. Glucose would arise as a result of the action of the small quantity of glucanases found in the 
Table 3. Composition of the hydrolysates of permethylated glucans following acetylation

Composition was determined by making five copies of the GLC traces, cutting each peak and weighing it. Identification of the CI fractions was from mass spectra analysis.

\begin{tabular}{|c|c|c|}
\hline $\begin{array}{l}O \text {-Methyl-D-glucitol } \\
\text { acetate derivative }\end{array}$ & Type of linkage & $\begin{array}{l}\text { Percent } \\
\text { composi }\end{array}$ \\
\hline $\begin{array}{l}\text { Pustulan } \\
\text { 2,3,4,6-Tetra- } O \text { - } \\
\text { 2,3,4-Tri- } O- \\
\text { 2,4-Di- } O-\end{array}$ & $\begin{array}{l}\text { Non-reducing end group } \\
(1 \rightarrow 6) \\
\text { Branch point C-1, C-2, C-6 }\end{array}$ & $\begin{array}{r}6 \\
87 \\
5\end{array}$ \\
\hline $\begin{array}{l}\text { Laminarin } \\
\text { 2,3,4,6-Tetra- } O \text { - } \\
\text { 2,4,6-Tri- } O- \\
\text { 2,4-Di-O- }\end{array}$ & $\begin{array}{l}\text { Non-reducing end group } \\
(1 \rightarrow 3) \\
\text { Branch point C-1, C-3, C-6 }\end{array}$ & $\begin{array}{r}8 \\
74 \\
7\end{array}$ \\
\hline $\begin{array}{l}\text { CI Fraction } \\
\text { 2,3,4,6-Tetra- } O \text { - } \\
\text { 2,3,4-Tri- } O \text { - } \\
\text { 3,6-Di- } O \text {-methyl-2- } N \text {-methylglucosaminitol acetate } \\
\text { 3-O-methyl-2- } N \text {-methylglucosaminitol acetate }\end{array}$ & $\begin{array}{l}\text { Non-reducing end group } \\
(1 \rightarrow 6) \\
(1 \rightarrow 4) \\
\text { Branch point }\end{array}$ & $\begin{array}{r}11 \\
10 \\
62 \\
7\end{array}$ \\
\hline
\end{tabular}

purified chitinase. Total acid hydrolysis of the CI fraction showed it to be composed of the monosaccharides glucosamine and glucose. The $\mathrm{CI}$ fraction was resistant to further digestion by either chitinase or Zymolyase $100 \mathrm{~T}$ but was degraded by purified $\beta$-(1,6)-glucanase. This result suggested that the chitin was linked to $\beta$-(1,6)-glucan. Analysis of the permethylated alditol acetate derivatives of the CI fraction was done by GLC using the same derivatives of pustulan and laminarin for comparison. The major GLC peak of the CI fraction did not correspond to either the 2,3,4- or 2,4,6-trimethylglucitol peaks of pustulan and laminarin, respectively. The permethylated alditol acetate derivatives of the CI fraction were further analysed by GLC-MS. The mass spectrum confirmed that the major GLC peak (Fig. 2, peak 3) did not correspond to either 2,3,4- or 2,4,6-tri- $O$-methylglucitol acetate (Bjorndal et al., 1967; Wong et al., 1980). It did, however, correspond to 3,6,-di-O-methyl-2- $N$-methylglucosaminitol acetate (the major peak expected from chitin). Besides this major peak, three other peaks were identified. These peaks (Fig. 2, peaks 1, 2 and 4) were characterized from the mass spectra fragmentation pattern as: 2,3,4,6-tetra- $O$-methylglucitol acetate (terminal derivative of a glucan), 2,3,4-tri- $O$-methylglucitol acetate (major derivative from $\beta$-(1,6)-glucan) and 3-O-methyl- $N$-methylglucosaminitol acetate, respectively. The identification of the latter peak provides evidence for the covalent linkage of chitin to $\beta$-(1,6)-glucan through a glycosidic linkage at position 6 of $\mathrm{N}$ acetylglucosamine and position 1 of the glucose in the glucan. It is still possible that the sugars are linked via amino acids as proposed by Sietsma \& Wessels (1979). A similar study was done using mid-exponential-phase yeast cells instead of spheroplasts, since it is known that chitin is overproduced by regenerating spheroplasts of $C$. albicans (Elorza et al., 1985; Gopal et al., 1984a); the characteristic ZI, ZII and CI, CII fractions were again isolated by gel permeation chromatography after enzyme hydrolysis. The $\mathrm{CI}$ fraction was resistant to further digestion with either chitinase or Zymolyase but susceptible to $\beta$ - $(1,6)$-glucanase digestion. It therefore appears that a similar glucan structure is present in the native wall of $C$. albicans.

From this work it would appear that there is a covalently linked glucan-chitin complex in the cell wall of $C$. albicans, consisting of a linear long-chain chitin backbone with $\beta$ - $(1,6)$ side chains joined via $\beta$ - $(1,6)$ linkages. It is possible that there are $\beta-(1,3)$-glucan chains joined to the $\beta-(1,6)$ glucan since the alkali-insoluble fraction had been treated with Zymolyase 100T before treatment with chitinase. The reason for the inability of the hydrolytic enzyme to hydrolyse all the linkages is probably due to this glucan-chitin linkage as well as to the highly branched structure. It has been suggested that glucan complexing with chitin prevents the crystallization of chitin in Schizophyllum commune (Sietsma \& Wessels, 1979). The existence of a glucan-chitin complex in $C$. albicans would account for the insolubility of this cell wall glucan fraction. 
This work was supported in part by the Medical Research Council of New Zealand. R.S. was a recipient of an MRC Scholarship. We wish to thank Dr R. A. Franich, NZ Forest Research Institute, for doing the mass spectral analysis.

\section{REFERENCES}

Bishop, C. T., Blank, F. \& Gardner, P. E. (1960). The cell wall polysaccharides of Candida albicans: glucan, mannan and chitin. Canadian Journal of Chemistry 38, 869-881.

BJORNDAL, H., LindBERG, B. \& Svensson, S. (1967) Mass spectrometry of partially methylated alditol acetates. Carbohydrate Research 5, 433-440.

BorchardT, L. G. \& PiPER, C. V. (1970). A gas chromatographic method for carbohydrates as alditol acetates. Tappi 53, 257-260.

Dubois, M., Gilles, K. A., Hamilton, J. K., Rebers, P. A. \& SMITH, F. (1956). Colorimetric method for determination of sugars and related substances. Analytical Chemistry 28, 350-356.

Elorza, M. V., Rico, H. \& Sentandreu, R. (1983). Cell wall composition and protoplast regeneration in Candida albicans. Antonie van Leeuwenhoek 49, 457469.

Gopal, P. K., Sullivan, P. A. \& Shepherd, M. G. $(1984 a)$. Metabolism of $\left[{ }^{14} \mathrm{C}\right]$ glucose by regenerating spheroplasts of Candida albicans. Journal of General Microbiology 130, 325-335.

Gopal, P. K., Sullivan, P. A. \& Shepherd, M. G. $(1984 b)$. Isolation and structure of glucan from regenerating spheroplasts of Candida albicans. Journal of General Microbiology 130, 1217-1225.

Gopal, P. K., ShePherd, M. G. \& Sullivan, P. A. (1984c). Analysis of wall glucans from yeast, hyphal and germ-tube forming cells of Candida albicans. Journal of General Microbiology 130, 3295-3301.

HAKomori, S. I. (1964). A rapid permethylation of glycolipid and polysaccharide catalysed by methylsulphonyl carbanion in dimethylsufoxide. Journal of Biochemistry 55, 205-208.

Hubbard, M. J., Surarit, R., Sullivan, P. A. \& SHEPHERD, M. G. (1986). The isolation of plasma membrane and characterisation of the plasma membrane ATPase from the yeast Candida albicans. European Journal of Biochemistry 154, 375-381.

Kitamura, K. \& Yamamoto, Y. (1972). Purification and properties of an enzyme, Zymolyase, which lyses viable yeast cells. Archives of Biochemistry and Biophysics 153, 403-406.

Mol, P. C. \& Wessels, J. G. H. (1987). Linkage between glucosaminoglycan and glucan determine alkali-insolubility of glucan in walls of Saccharo- myces cerevisiae. FEMS Microbiology Letters 41, 9597.

Molano, J., Duran, A. \& Cabib, E. (1977). A rapid and sensitive assay for chitinase using tritiated chitin. Analytical Biochemistry 83, 648-656.

Molano, J., Bowers, B. \& Cabib, E. (1980). Distribution of chitin in the yeast cell wall. An ultrastructural and chemical study. Journal of Cell Biology 85, 199212.

SCheP, G. P., Shepherd, M. G. \& Sullivan, P. A. (1984). Purification and properties of a $\beta-1,6-$ glucanase from Penicillium brefeldianum. Biochemical Journal 223, 707-714.

SHEPHERD, M. G. (1987). Cell envelope of Candida albicans. CRC Critical Reviews in Microbiology 15, 7-25.

Shepherd, M. G. \& Sullivan, P. A. (1976). The production and growth characteristics of yeast and mycelial forms of Candida albicans in continuous cultures. Journal of General Microbiology 93, 67-74.

Sietsma, J. H. \& Wessels, J. G. H. (1979). Evidence for covalent linkages between chitin and $\beta$-glucan in a fungal wall. Journal of General Microbiology 114, 99108.

Sullivan, P. A., Yin, C. Y., Molloy, C., Templeton, M. D. \& SHEPHERD, M. G. (1983). An analysis of the metabolism and cell wall composition of Candida albicans during germ-tube formation. Canadian Journal of Microbiology 29, 1514-1525.

Trevelyan, W. E., Proctor, D. P. \& Harrison, J. G. (1950). Detection of sugars on paper chromatograms. Nature, London, 166, 444-445.

Tronchin, G., Poulain, D., Herbaut, J. \& Biquet, J. (1981). Localization of chitin in the cell wall of Candida albicans by means of wheat germ agglutinin. Fluorescence and ultrastructural studies. European Journal of Cell Biology 26, 121-128.

Wong, C. G., Sung, J. S. \& Sweeley, C. C. (1980). Analysis and structural characterization of amino sugars by gas-liquid chromatography and mass spectrometry. Methods in Carbohydrate Chemistry 8 , 55-65.

YU, R. J., Bishop, C. T., COOPER, F. P., BlanK, F. \& HASENClever, H. F. (1967). Glucans from Candida albicans (serotype B) and from Candida parapsilosis. Canadian Journal of Chemistry 45, 2264-2267. 